\title{
Lifelong Learning and Virtual Communities in the Public Administration: A Case Study in Italy
}

\author{
doi:10.3991/ijac.v2i3.945 \\ Luigi Colazzo, Andrea Molinari and Nicola Villa \\ University of Trento, Trento, Italy
}

\begin{abstract}
This work introduces our experience in developing $\mathbf{L 3}$, a project that aims at developing an educational and collaborative environment oriented towards public employees of our provincial administration (Autonomous Province of Trento - P.A.T. - Italy). Our research group has been involved for years in the design and development of elearning applications; in the new $L 3$ system we realized that the simple re-design of a traditional e-learning system was too limited with respect to the needs, especially concerning users' active participation in a more "social" sense. This work presents the first results of the project, which has a four year duration (2009-2011), and its development towards a future "Private Community Environment".
\end{abstract}

Index Terms-e-learning, lifelong learning, virtual leaning communities, web 2.0

\section{INTRODUCTION}

The context of this work is a Technology-Enhanced Learning application developed autonomously by our work group. This system was initially configured as a Learning Management System directed at the reality of universities and based on the metaphor of virtual learning communities.

This choice is motivated because the metaphor of course, the most used by the e-learning systems, is not able to cover all the interactions that may take place within working groups, aggregative and collaborative structures that we can define in a first instance as "communities".

Our first experimentation was based on the e-courses, structures strongly linked to the real courses held in real classrooms. Subsequently, our choice has been directed, as mentioned before, at different structures (virtual communities) or e-Communities. A new dynamic application web was born called On Line Communities, able to meet the information and training needs of the Faculty of Economics of the University of Trento.

The collaborative approach [9] [10] is a very strong incentive for us for the development of On Line Communities; the philosophy that led us to rebuild the system was to allow the exchange of users' experiences within a virtual environment and within well-defined areas known as "communities". This approach is very different from, for example, the traditional ones of other e-learning applications. The community is a container ready for didactic processes, but not only. It can contain anything that is an aggregation of people around a scope using virtual spaces on the web, such as research teams, recreation groups, friends, secretariats, board of directors, colleagues. Here we wish to describe our work in this field, and in particu- lar the evolution of our platform from the typical concept of e-learning to the wider concept of lifelong learning, connected to the new technological innovations of web 2.0.

The work is organized as follows: the second section will describe the technological base of our discussion, $O n$ Line Communities platform based on the metaphor of virtual learning communities. The third section will introduce the Lifelong Learning project for the Public Administration of our territory, the Autonomous Province of Trento in Italy. In the fourth section we will describe some new characteristics of the platform, implemented for the real needs of our Public Administration. In particular the implementation of a video cast service, the integration of a SCORM player that supports the publication of virtual lessons and the evolution of the platform to services oriented more towards the collaborative approach, like what at the moment we define as the term "web 2.0". For this last part it is important to analyze the impact of that adoption in a system directed at the employees of a Public Administration.

\section{ON LINE COMMUNITIES}

Ten years ago the Faculty of Economics of the University of Trento decided to have a software system able to enrich its traditional teaching as an extension on the Web. The first aim was to settle the increasing number of teachers' personal web pages into a single platform. To pursue this result it was necessary to have a Learning Management System (LMS), capable of supplying a virtual environment able to support the educational courses of the Faculty. The resulting system was named On Line Courses and was developed by our Laboratory. Being a quite traditional LMS, in 2002 some observations convinced us to redesign the software:

- The needs for cooperation within the academic environments in extending to all activities that constitute the context in which didactics take place, not just specific "lectures";

- models of teaching / learning (such as learning by problems, learning by projects, cooperative learning and their combinations) can hardly be connected to the e-Course, especially when the software directly represents the metaphor of traditional courses;

- the organizational didactic scenario changed with new regulations made by academic institutions, and these changes inevitably reflected on the LMS functionalities. It is important to note that these types of changes are usually the result of a debate process in which both elements of cooperation and negotiation interact; 
- the didactics of a university do not consist of a set of studies and tests only, but these activities are inevitably intertwined with the university's organization and its information system;

- in an academic context, not everything concerns teaching: for example, it is not correct to represent a faculty only as a container of degree courses because it is not possible to cover other different experiences (as, for example, a group of student involved in the sport groups of the university).

To answer these (and other) needs another founding paradigm, with at least three basic characteristics, was needed,

1. Generalization with regard to educational settings;

2. suitability to support cooperation processes;

3. capability of modeling and preserving organizational structures and roles of the educational institution.

This new way of conceiving the collaboration platform was found in the concept of virtual community. The system that arose, called On Line Communities [11], was born in 2003 and has been running since February 2005. Our work started before the boom of web 2.0 [12], that has now invaded and changed the way people think and build services on the net.

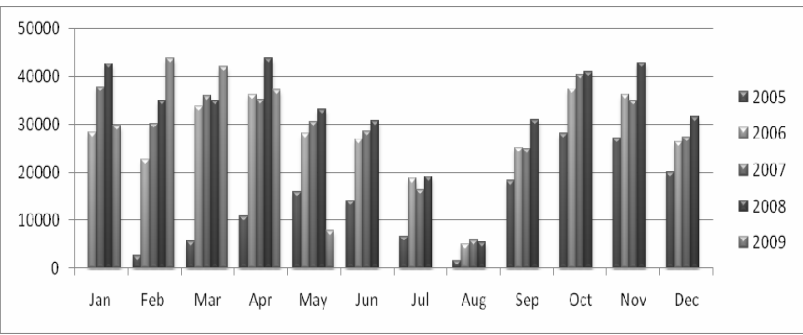

Figure 1. On Line Communities Accesses (May 2009)

In our opinion the definition of Jenny Preece [1] about on line communities seems appropriate to describe the metaphor that we adopt, indicating the communities as a site in the cyberspace consisting of:

- individuals who interact socially while seeking to satisfy their own needs taking on specific roles such as leader or moderator;

- a common purpose, for example an interest, a need, an exchange of information or a service that justifies the existence of the community;

- policies in the form of tacit assumptions, rituals, protocols, rules and laws that guide the interactions among individuals,

- information systems that support and mediate social interactions and offer a sense of belonging.

The sharing and transmission of knowledge among the various users are two of the possible aims of the virtual community (VC). In the measure in which one learning community contributes to the pursuit of these two specific objectives it can be called a learning community or, even better, a "Virtual Learning Community". The third issue that characterizes a virtual community, in the approach that we are adopting, is connected to the cooperation among its participants. Our work is based on the concept of VCs adopted by Lèvi [2] [3] [4]: he defined the virtual communities as groups of people who are in contact be- cause they share some kind of knowledge and interest, corresponding with each other using interconnected computers in a cooperation process. This approach differs from that adopted by other authors, such as Beamish [5] that considers the virtual community as a group of people who communicate using computer mediated communication tools. The participants of these communities are physically in different places yet, they can still exchange information on common interests in a communitarian way. Rheingold [6] considers VCs as an emerging social phenomena. More relevant to us is the approach of Jones [7] [8] that separates conceptually the technological structure of VCs (named virtual settlement) from the community itself.

After these observation we can sum up the main characteristics of a virtual community in our application as follows:

- Each Community offers many services to registered users that have different roles/permissions inside the community.

- The services are general applications that enable the users to communicate in synchronous and asynchronous way, to publish contents, to exchange files, to coordinate events, etc.

- Services offered by a community are activated by a manager of the community according to the needs, and the users of a community can use them with different rights and duties.

- Rights/duties in the community are different from rights/duties for the services.

- Communities can be aggregated into larger communities with hierarchic mechanisms and infinite nesting levels. Communities can also be aggregated in an arbitrary way into larger communities disregarding the possible position of a hierarchical structure, in a sort of "transversal" link that overcomes the concept of "hierarchy" and follows the idea of "mesh". Thanks to these features, a complex but powerful mechanism of propagation of services/roles/permissions/rights/

- duties can be set among communities of the same branch or of different branches.

- All users are recognized by the system and by the community: people external to the system can see public parts of the community (services, material, contents etc.) only if the managers allow this (ex. a blog of one community could be opened to external contributions).

- Services can take advantage of the "mesh" structure of On Line Communities to provide some interesting though non-existing features, like "transversal wikis", or "merged blogs". One blog, in fact, can be the "fusion" of all blogs of children's communities, or a wiki can take the definition transversally from all wikis in related communities.

- Last but not least, a VC is the container for collaboration processes not limited to educational activities, but for any collaboration activity needed in an organization. Research teams, recreation groups, friends, meetings, conferences, secretariats, board of directors, colleagues, next social dinner, anything could be an aggregation of people around a scope 
that can take advantage of the virtual spaces offered by the Virtual community.

The core of the application is composed by some abstract entities, i.e. virtual communities, as aggregation of people to which some communication services are available in order to obtain certain objectives. With this approach, it could be possible to represent all the hierarchical relationships between different types of educational communities (such as Faculties, Didactic Paths, Master Degrees, Courses, etc.), just as any other relationship among communities inside organizations.

\section{THE LIFELONG LEARNING PROJECT (L3) FOR THE AutONOMOUS PROVINCE OF TRENTO}

L3 (Lifelong Learning) is a project to be implemented by our university, commissioned by the Autonomous Province of Trento (P.A.T.) as an e-learning platform aimed at becoming a technological environment for training and collaboration projects within the P.A.T. itself and connected offices. The aim of our work is mainly technological: our task is to supply the Autonomous Province of Trento with a tool enabling to improve internal training processes. The system we are developing has, however, some peculiar characteristics:

- The system will operate on a territorial basis.

- The system should be able to guarantee temporal continuity of the training experience which goes beyond the single case of training and ideally is extended to at least many years.

- The system must be tightly integrated with the information system of the P.A.T., in particular with the Personnel Management system that manages the history of all the training activities performed by each single employee in P.A.T.

- The system should be able to support different collaboration activities, not only those strictly related with training activities.

These circumstances, together with previous experiences in creating e-learning platforms within the university, have induced us to use once again the metaphor of "virtual learning community".

The first lifelong learning project that we have developed was directed at the managers of our Public Administration and in particular on the theme of e-procurement. We set up a group of courses, explaining to the participant the mechanisms that underlie the e-procurement: the name of the project was ESPERTO (E-learning for the development of e-procurement in Trentino) ${ }^{1}$.

The second step was the development of a bigger project, named L3 (Lifelong Learning), directed at all the training courses for all employees of our Public Administration.

\section{NEW SERVICES IN A LIFELONG LEARNING APPROACH}

In the development of the new platform, we have decided to implement a set of new services, with the aim of

1 The project was co-financed by CNIPA (Italian National Center for Informatics in the Public Administration). Project ID $\mathrm{n}$. $36672 / 335$ supporting the training activities of the employees of our Public Administration.

It was decided to develop three different lines of services:

a. Multimedial services, like the possibility to play the video of the lesson, together with the slides and notes;

b. Training activities tracking services, like the possibility to use SCORM (Sharable Content Object Reference Model) material;

c. Web 2.0 and Social Network services, more oriented to increase the collaboration levels among the participants.

\section{A. Multimedial Services}

One feature we want to integrate into our VC platform is the possibility of accessing a particular LO concerning videos of lectures, providing this video with some extra features such as:

- audio/video part of the lecture, in medium quality/resolution, but in such a format that the learner can recognize the progression of the lecture and is able to hear very well (in our preliminary experiments, and in other experiments [13] audio quality has been demonstrated to be fundamental);

- slides used by the teacher, transformed in JPEG single files to be synchronized with lecture progression;

- time-line of the presentation, where the user can interact to change the pace of the lecture;

- index of the presentation, for hyper textual navigation into the lecture contents;

- time bar for controlling/playing/pausing the presentation.

All these components are assembled in a unique learning object using the SCORM standard, thus creating a unique package that represents a highly realistic substitute of what happened during the physical lecture. This is what we imagine to be the best replacement to having being physically at the lecture, and we believe that, in some sense, this learning object could have some extras that are even better than being there: for example, the possibility of hyper textual navigation through the lecture slides.

The necessity of this type of service came up because we prepared a training path distributed on the territory.

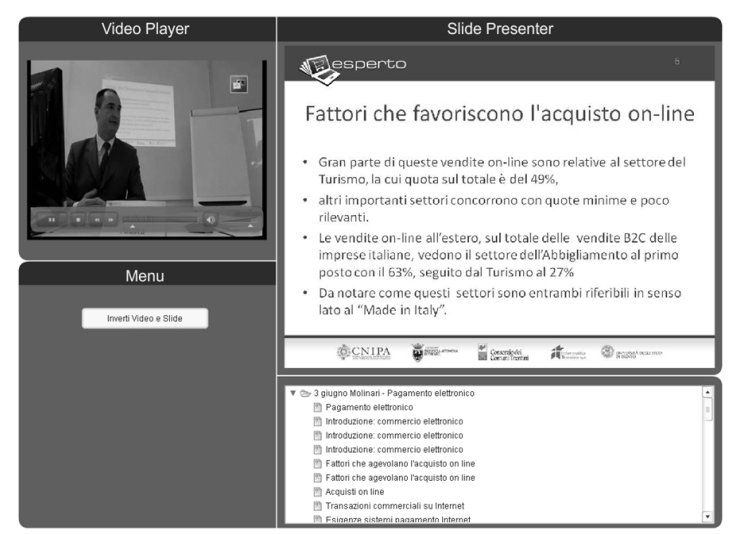

Figure 2. Video cast service inside On Line Communities 
Lectures on e-procurement, that are dedicated to the staff of our Province, are not held in one location only (for example the central building of our local government), but are divided into several collecting centers on the territory. The Autonomous Province of Trento, in fact, is characterized by a predominantly mountainous territory, with a main centre (Trento, the capital of the Province), and many other smaller towns in other surrounding valleys. Some of these towns, in particular, do not have easy connections to Trento, due to their geographic position; in some cases these towns / villages can be reached only through Alpine passes. In this logistically-complex situation, the benefits of distance learning is quite obvious: it is not a problem of "distance" (like Canada, Australia and other geographically wide countries), but it is more a "social" problem, in order to help the local employees to attend the course, without the daily trip to the capital of the Province. For these reasons, we set up some educational centers in the main towns of the provincial territory: people no longer have to move to the capital, but will simply reach the nearest aggregation center, and follow the lecture through video-conferencing system.

As an example, we have represented on the map of our Province (Fig. 3 ) the location of the centers where the eprocurement's courses were held. The greatest distance from the peripheral areas to Trento is about $100 \mathrm{Km}$, that means at least two hours by car (due to transportation complexity), weather permitting (snow conditions are quite frequent).

This geographical configuration, represented in the map, has induced us to create a new service in our system, which allows the more realistic presence of people at the lecture, and the possibility of accessing off-line the more realistic representation of what happened during the "real lecture", i.e., the live lectures held in the central classroom. Of course, the service will not replace the relationship which takes place between the teacher and the students during lessons, but could be a supporting service. Out of a total of hours of lectures $30 \%$ will be completely remote, with few people physically in front of the teacher while the others are scattered all over the Province. Each of the five classes will be of about 20 people.

These conditions pushed us to improve the quality of our educational material, which means:

- it was our choice to create, on the one hand, the most realistic surrogate of face-to-face lectures: webcasting enriched with the features explained above has been our choice

- and on the other, to create material that could be easily re-used and manipulated in the future, and this is where the SCORM standards come out.

\section{B. Tranining activities tracking services}

Due to the relevance for the L3 project of the reuse of educational material, and in order to meet the demands of the provincial Public Administration, we decided to package the didactic material (including the webcasting material) using the SCORM standard, thus providing the opportunity to use the didactic material within a SCORMcompatible system.

At this point, with SCORM-compatible educational material available and ready to be used by participants, we had different options for including this kind of material into the platform. This operation could mean different

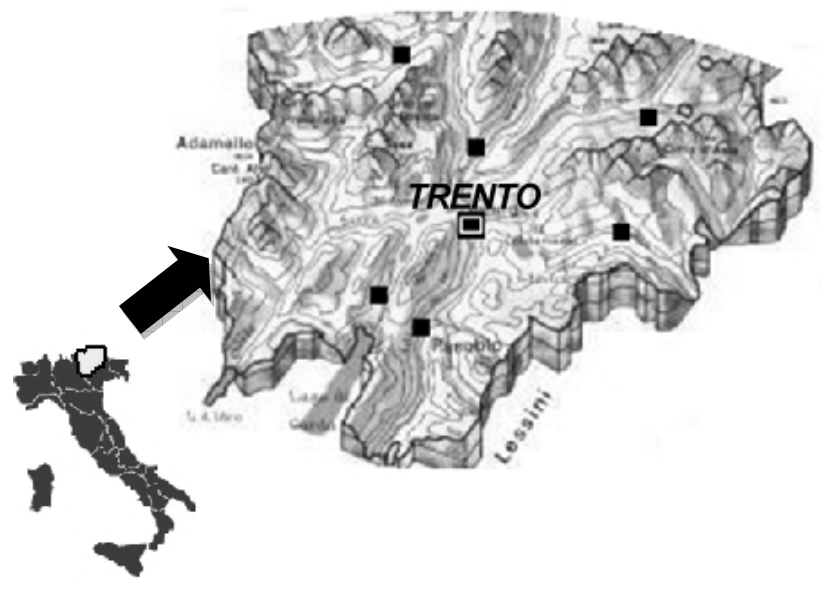

Figure 3. The didactic collecting poles on the Trentino territory

solutions, more or less invasive compared to the previous version of the platform that was not SCORM-compliant. The following are the two extreme solutions, with many variations in the middle:

- the simplest solution, upload a simple SCORM package (a .zip file) created with external tools, and let the user download it and play it autonomously, outside the platform and using a SCORM player;

- or, in contrast, create a SCORM-compatible editing environment directly inside On Line Communities, and let the users follow SCORM-based educational material from inside the platform: this is in theory the perfect solution, but it is really complex and costly due to continuous evolution of these tools and standards, and the necessity of creating a SCORMcompatible authoring tool.

In a first experimental phase the first approach was chosen in order to supply our participants with the material in the shortest of times. Two questions arose from the conclusion of the Esperto project:

- Are the users really using the material that they have downloaded?

- How long do users stay on the didactic materials?

These questions were not considered in a first step, because we wanted to test the platform in a different context from the university. After that we chose to follow the second solution, which allows users to use the SCORM material directly in the platform. Following this approach through the use of a dedicated player, we can understand in more detail what users actually do with the materials.

In fact, a SCORM player is able to:

- track the actions performed by users (what content they have used, the quiz statistics, etc.);

- plot the time performed by users to conclude a lesson (or part of it).

We have integrated into the platform a commercial player, providing the users with a full statistics system on their actions. In this way the teachers have the opportunity to know the real use of their virtual lessons. Also each participant can monitor the commitment that is dedicating to a specific training course. 


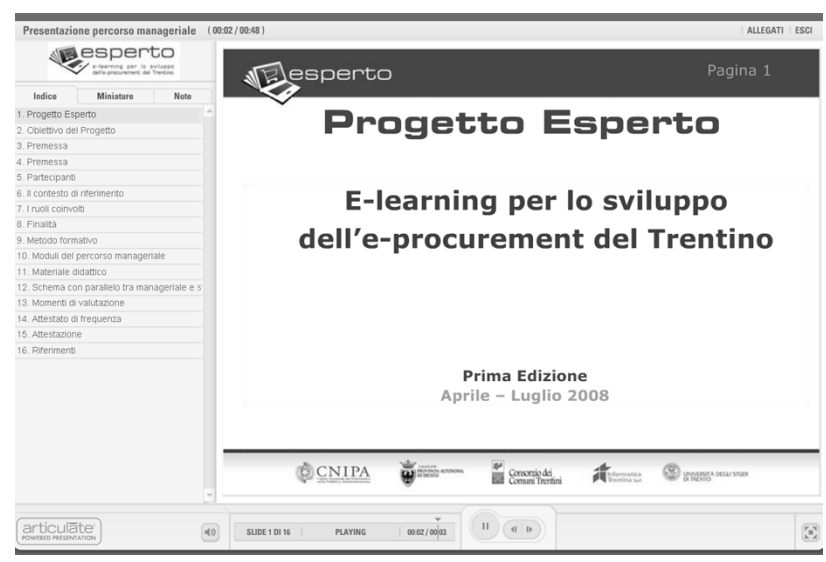

Figure 4. SCORM slide lesson, with audio

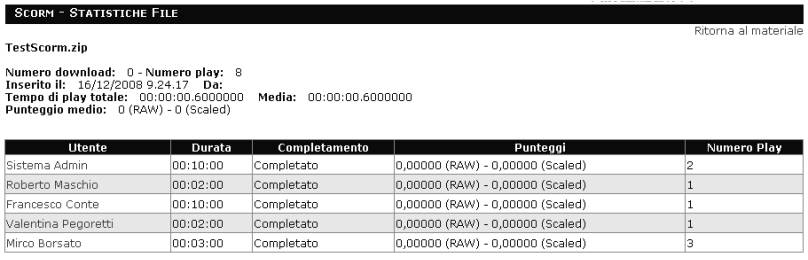

Figure 5. Statistics of the material usage

\section{Web 2.0 and Social Network services}

If we look at the whole range of application fields where we are using On Line Communities, the platform clearly evidences its nature of a collaborative environment that wants to stimulate the participation and put to value users' cooperative work. Today, with the advent of new communication and collaboration paradigms, On line Communities has become an example of a computer support cooperative work system (CSCW) dedicated to teaching/learning. In recent years, we extended our system to functionalities and services typical of Web 2.0. However, some relevant differences exist between the approaches used by web 2.0 applications and the ones used in On Line Communities. To overcome these differences, a changing of the rules used in the virtual space is required, and these changes have a direct influence on the entire architecture of the system.

The cooperative virtual space of On Line Communities is actually a closed environment. The users participate in the activities inside the system directly with their real identity. In fact, a person who enters a virtual community of our system is authorized firstly by the platform administrator (for certifying user's credentials), and then by each community administrator for each community the user wants to enroll with. Once the user is accepted inside the community, from that moment he/she is automatically in contact with all the people inside the community. This is the pillar of the virtual community: I am in the community because I share its scope, and all the people of the community have more or less the same interests / objectives / tasks. Following this logic, the user is not obliged to declare, accept, or manage his/her contacts inside that community: s/he will never have to face the "domino" effect of most social networks, where you will be connected to a friend of a friend of a friend. Of course, On Line Communities allows each user to manage a friends' lists, but this is different from managing community members. The differences between "friends" and "community members" are very precise and marked, and the user is allowed by the platform to manage these two different concepts.

Given that the increase of social interactions is not a negative aspect in principle, the risks deriving from the direct use of the most used social network approach (like for example the approach used by Facebook [14]) into an environment with different aims are very high. According to some recent statistics [15], the majority of users who use the so called "social networks services" are concentrating on the well known "people surfing": navigating into the friends' profiles, look at pictures, personal information, etc. We are aware of the clear phenomenon that is emerging from friends' social network [16]; it is true that the action of adding a person to the friends' list requires an approval, but it is also true that a user can see at any moment the people connected to his/her friends; a critical consequence is to become implicitly a friend of my contacts' friends, thus starting a sort of recursion in the friends' list of friends.

The circumstances that we consider favorable in our system (lack of anonymity and control of the external accesses) have origin in two explicit requirements of our Faculty of Economics. The exclusion of anonymity is the result of a belief that normally indicates that the anonymity into virtual learning environment should be banned, so that the actors cannot shirk from their responsibilities. The second circumstance (access control) stems from the will of a substantial number of teachers to block the publication on the network the Learning Objects of their own courses. These choices made the system impermeable to the users' social dynamics, or to the communities existing in the social networks.

To overcome these limits without affecting our constraints requires a radical change of the system architecture that sees the person as a member of one or many communities. In the web 2.0 applications, the participants exist as individuals who, for example, can create themselves a specific community. The rethinking of the system with these ideas is changing our community system to a sort of "community 2.0 " system: we like to define it a "Private Community Environment" (PCE). A space where each user can create a list of the personal contacts (classified by gender) which interact, manage the personal services (like, for example, the blog), import the content published in other platform (like, for example, Facebook, Twitter, etc.).

Following this line, we studied how to modify the architecture of our system, as we wanted to implement the good part (from our perspective) of the incredible revolution introduced by social networks. Our aim was to transform our virtual communities platform into a sort of bridge system between the classical methodology followed in the most famous LMSs (like for example Moodle [17]) and the new web 2.0 and social networks applications (like for example Facebook, MySpace and Flickr), without losing the focus on the learning processes.

The architecture that we developed has two fundamental goals:

- As we said, to make our system more permeable to all experiences that take place inside the web, including applications for social networking and Web 2.0;

- Keep control, up to a certain level, of the actions taken by users of our system. In fact, our context is 
connected to learning environments / academic settings, and not directly to leisure time.

Following these approaches, many drastic changes have been introduced into the platform, moving the focus from "community" to "user". As an example, when the user connects to the system, the user' personal home page and its services are presented, trying to create a real Personal Learning Space (PLS).

We imagine the new users' Personal Learning Space as an aggregation of two distinct environments. The user will be free to decide what part of his/her relations and contents to import (into On Line Communities) or export (to social networks applications). This solution required a thorough review of many parts of On Line Communities, and in particular the management of users' roles and permissions.

This approach has different values, in particular regarding the teaching strategies; in fact exporting the contents outside an e-learning platform could accentuate the social role of the educational institution as a source of knowledge and of better didactic practices. On the one hand, this solution gives the user more freedom than in a classical LMS but, on the other, it is more difficult for didactic institutions to be implemented. In fact, while the institutions are becoming a knowledge centre through the participation of its members, at the same time they are being exposed to the risk of the complexity and the personal relationships of its members.

The user can access the list of communities where $\mathrm{s} / \mathrm{he}$ is enrolled in. But together with this, the user finds a set of services that are typically connected to his/her own person, a sort of personal space within the system. The services are "general", so in this condition the user will use services that are at "personal" level. This can be repeated and nested when the user enters a community: s/he will find (more or less) the same services, but this time these will be the services of that community, with different permissions, roles, list of contacts etc. A typical example is the Blog service: when I am inside my PLS, the Blog is my blog, when I am inside the community "workgroup XWZ", the service Blog refers to the blog of that community: same service, totally different context and contents, yet the role of the user could be totally different. Finally, thanks to the inheritance mechanism among communities provided by the platform, the blog of that community can be merged with the blogs of parent community/ies, or with the child communities, or with sister communities (children of the same parent community).

\section{CONCLUSIONS}

Our first experimentation, focusing on a small part of the public employees of our Autonomous Province, was very important for the L3 project. The most useful services for our public employees have been identified; in particular the possibility to use web cast and SCORM material is a key factor for the final success of the project.

What clearly emerged from our experiments is an interesting perspective for a virtual community system like ours.

Firstly in our experimentation we have observed that public institutions need virtual collaboration spaces, places on the web with collaboration and web 2.0 tools available for their employees / partners. Secondly tradi- tional LMS are not suitable for these needs, mainly because they are oriented at e-learning, and their pillars are metaphors like "classroom", "class", "course", rather than other ideas more oriented to collaboration, like "community", "group", "team", "secretary", "board", "office”, "department". A classroom is of course a community where collaboration is oriented towards a specific target, i.e., training. This is just one component of collaboration, a very important one, but is certainly not the only one that companies / public administrations need.

The evolution of the platform is now available for a second experimentation, directed at a larger group of employees; in particular we are setting up a group of courses, with more or less one thousand of people participating. This second step will be necessary to understand the final requirements that we will integrate into the platform; for this experimentation we are providing some new collaborative / web 2.0 services like the wiki, blog, workbook, etc, that follow the hierarchical structure of On Line Communities. These services were totally developed by our team and are completely suitable with the generalization of community: each service manage the complex mechanism of roles, permissions, duties, rights, typical of a communities based system, combined with standard web 2.0 services, like the integration of YouTube, SlideShare, etc.

\section{REFERENCES}

[1] Preece J., (2001) Online Communities - Designing Usability, Supporting Sociability, Wiley, Milano 2001

[2] Lévy P., (1994) La Découverte, Paris, 1994

[3] Lévy P., (1995) Qu'est-ce que le virtuel?, La Découverte, Paris, 1995

[4] Lévy P. (1999), Cyberculture, Feltrinelli Milano 1999

[5] Beamish A., (1995) Communities on-line, doctorate thesis of Anne Beamish

[6] Rheingold H., (1993) The Virtual Community, 1993 (itlian translation Comunità virtuali, Sperling \& Kupfer, Milano, 1994).

[7] Jones S. G., (1995) Cybersociety, Sage, London, 1995.

[8] Jones S. G., (1997) Virtual Culture, Sage, London, 1997.

[9] Anderson C. (2006), The long Tail: how endless choice is creating unlimited demand. Random House Business Books, N.Y.

[10] Chambers S.A. (2005), Working on the democratic imagination and the limits of deliberative democracy, Pol Res Q 58(4):619-623

[11] Colazzo L., Conte F., Molinari A., Villa N. (2007), Real communities vs. Virtual communities: structural adaptation of a Learning Management System. In: World Conference on E-Learning in Corporate, Government, Healthcare, and Higher Education 2007, Chesapeake (VA): AACE, 2007. p. 2416-2423. "E-Learn 2007 Conference", Quebec City, October 2007

[12] O'Reilly, T. (2005). Web 2.0: Compact Definition? Retrieved

[13] Grant M., Jongpil Cheon, The Value of Using Synchronous Conferencing for Instruction and Students, Journal of Interactive Online Learning Volume 6, Number 3, Winter 2007

[14] Facebook. http://www.facebook.com/, 2009.

[15] Compete.com (2007), Facebook Activity Breakdown, August 2007. http://blog.compete.com/2007/09/14/facebook-activitybreakdown-application/. October 2008

[16] Boyd D. (2006) Friends, friendsters and mySpace Top 8: writing community into being on social network sites. First Monday 11(2), December. http://www.firstmonday.org/ issues/issue11_12/boyd. Accessed October 2008

[17] Moodle. http://www.moodle.org, 2009.

\section{AUTHORS}

Luigi Colazzo is an associate professor at the Department of Computer and Management Sciences of the Uni- 
versity of Trento, Trento, 38100 Italy. (e-mail: luigi.colazzo@unitn.it). He is the scientific responsible of the LifeLong Learning project for the Autonomous Province of Trento (Italy).

Andrea Molinari. is a contract professor at the Department of Computer and Management Sciences of the University of Trento, Trento, 38100 Italy. (e-mail: andrea.molinari@unitn.it). He's the project manager of the LifeLong Learning project for the Autonomous Province of Trento (Italy).
Nicola Villa is a research scholar at the Laboratory of Maieutics of the University of Trento, Trento, 38100 Italy. (e-mail: nicola.villa@unitn.it).He's the accessibility and usability responsible of the LifeLong Learning project for the Autonomous Province of Trento (Italy).

This article was modified from a presentation at the ICELW 2009 conference in New York, NY, USA, June 2009. Submitted, May 28, 2009. Published as resubmitted by the authors on July, 1, 2009. 